\title{
In memory of Professor Robert W. Baldwin: Editor-in-Chief of Cancer Immunology, Immunotherapy 1976-2003
}

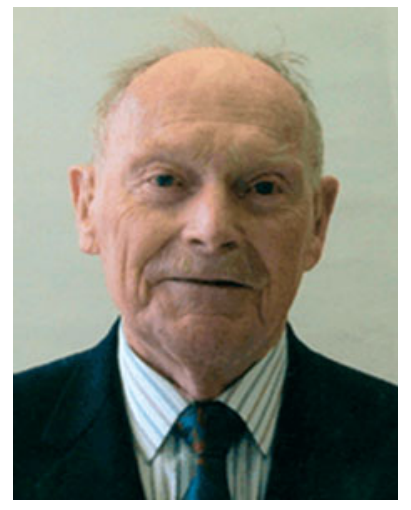

It is with very great sadness that the editors and publishers of Cancer Immunology, Immunotherapy announce the death of former co-Editor-in-Chief Professor Robert "Bob" Baldwin on 30 June 2012. Prof. Baldwin was one of the first to show, more than 50 years ago, that tumours were immunogenic in rodents and that immune memory could be adoptively transferred from a sensitised to a naive animal. A pioneer of the idea that tumours stimulate immune responses, he was appointed as an Editor-in-Chief of our journal-by far the oldest specialist journal in this field-in 1976.
With his many new ideas about Cancer Immunology, Immunotherapy as a journal and as a subject, he substantially moulded the development of both. Prof. Baldwin ran one of the best-known and most prestigious cancer research laboratories in the world and in the 1970s had more than 60 researchers at his centre in Nottingham. He published over 1,000 research papers during his career. After his retirement from active research and from the Editor-in-Chiefship of Cancer Immunology, Immunotherapy in 2003, he remained on the journal's Editorial Board.

Bob was a very unassuming person, a real gentleman. He was always ready to help others and actively supported the careers of his employees, ex-employees and many of his colleagues. Our deepest sympathies are with Robert Baldwin's family. He was very proud of them and their achievements.

An obituary to record and celebrate his many accomplishments and attributes will be published by the Journal in due course.

Enrico Mihich and Graham Pawelec, Editors-in-Chief 